\title{
Structural characterization of electrodeposited boron
}

\author{
ASHISH JAIN, C GHOSH ${ }^{\mathrm{a}}$, T R RAVINDRAN ${ }^{\mathrm{b}}$, S ANTHONYSAMY $^{*}$, R DIVAKAR $^{\mathrm{a}}$, \\ E MOHANDAS ${ }^{\mathrm{a}}$ and G S GUPTA ${ }^{\mathrm{c}}$ \\ Chemistry Group, ${ }^{\mathrm{a}}$ Physical Metallurgy Group, ${ }^{\mathrm{b}}$ Materials Science Group, Indira Gandhi Centre for Atomic Research, \\ Kalpakkam 603 102, India \\ ${ }^{\mathrm{c}}$ Department of Materials Engineering, Indian Institute of Science, Bangalore 560 012, India
}

MS received 27 January 2012; revised 29 May 2012

\begin{abstract}
Structural characterization of electrodeposited boron was carried out by using transmission electron microscopy and Raman spectroscopy. Electron diffraction and phase contrast imaging were carried out by using transmission electron microscopy. Phase identification was done based on the analysis of electron diffraction patterns and the power spectrum calculated from the lattice images from thin regions of the sample. Raman spectroscopic examination was carried out to study the nature of bonding and the allotropic form of boron obtained after electrodeposition. The results obtained from transmission electron microscopy showed the presence of nanocrystallites embedded in an amorphous mass of boron. Raman microscopic studies showed that amorphous boron could be converted to its crystalline form at high temperatures.
\end{abstract}

Keywords. Transmission electron microscopy; Raman spectroscopy; boron; electrodeposition.

\section{Introduction}

Boron carbide, containing enriched boron $\left({ }^{10} \mathrm{~B} \sim 65\right.$ at $\left.\%\right)$ is the control rod material for prototype fast breeder reactor (PFBR) in India (Babu et al 1996). It is synthesized by reacting elemental boron with carbon at temperature above $2073 \mathrm{~K}$ (Suri et al 2010). Elemental boron, in turn, is produced by a high temperature molten salt electrotwinning process (Nair et al 1992; Subramanian and Suri 2004). This process involves electrodeposition of boron from a melt comprising $\mathrm{KCl}(70 \mathrm{wt} \%), \mathrm{KF}(12 \mathrm{wt} \%)$ and $\mathrm{KBF}_{4}(18 \mathrm{wt} \%)$ on a mild steel cathode (Jain et al 2008). A pilot plant facility was set up at the Indira Gandhi Centre for Atomic Research, Kalpakkam, India, in order to develop this process suitable for the large scale production of elemental boron. The rate of high temperature reaction between elemental boron and carbon to form $\mathrm{B}_{4} \mathrm{C}$ is controlled by diffusion kinetics. The rate of diffusion in turn is controlled by size distribution of the particles and temperature of the reaction.

In general, the size distribution and crystallinity of particles of boron depend on the method and temperature of synthesis. The physical properties of the electrodeposited boron depend on the parameters of the electrotwinning process. In order to identify the crystallographic and microstructural characteristics of electrodeposited boron, transmission electron microscopic analysis was carried out. Although Miller (1960) reported that boron obtained by molten salt electrolysis was crystalline in nature, X-ray diffraction pat-

\footnotetext{
*Author for correspondence (sas@igcar.gov.in)
}

tern of the same in support of this conclusion was not reported in this study.

Marzik et al (2010) carried out lattice imaging of boron synthesized by plasma process using transmission electron microscope (TEM). Their studies showed large portions of both amorphous and $\beta$-rhombohedral crystalline boron in the powder sample. These authors studied the effect of process parameters on the crystallographic and microstructural properties of boron and reported that boron had emerged from the plasma torch as very open, loose and lacey agglomerates in which size of the boron particles ranged from 5 to $200 \mathrm{~nm}$ (Marzik et al 2009).

Evgeniya et al (2008) synthesized a high-pressure, hightemperature phase of boron and transmission electron microscopy and electron energy loss spectroscopic studies, he identified this phase to have an orthorhombic symmetry with 28 atoms per unit cell.

Pickering et al (2007) described a process for the synthesis of surface functionalized boron at room temperature. These authors analysed the size distribution of particles in the sample using TEM and observed that the particles fall in the size range of $1-45 \mathrm{~nm}$. The presence of boron was confirmed by scanning tunneling electron microscopy and electron energy loss spectroscopy.

Brian et al (2009) synthesized boron particles by gasphase pyrolysis of decaborane vapour at $1 \mathrm{~atm}$ and at 973$1173 \mathrm{~K}$. TEM images of these boron particles showed that the majority of the particles were in the size range of 10 $150 \mathrm{~nm}$ and that they were textureless and quasispherical. The $d$-spacings and intensities were consistent with those of $\alpha$-rhombohedral phase of boron, but the possibility of amorphous boron was not ruled out. 
Steeds and Wilson (1998) examined an amorphous boron sample and observed that a significant proportion of the particles were well crystallized in that sample. Examination of these crystalline particles by convergent beam electron diffraction technique revealed that they were orthorhombic with space group Pnma. These authors concluded that the presence of impurities in the material was responsible for crystallization.

In order to confirm possibility of the existence of a quasicrystalline phase of boron, Favia et al (1996) carried out high resolution electron microscopic and electron energy loss spectroscopic analysis of boron. They observed that in crystalline phase, creation of a large number of microtwins and stacking faults was the way that nature chose to disorder boron. The presence of these microtwins seem to be the major obstacle towards the formation of a quasicrystal. These authors could confirm the presence of icosahedral units in the amorphous phase. High resolution electron microscopic studies of the amorphous boron showed presence of some nanocrystals with typical size of $10 \mathrm{~nm}$.

Though several authors have carried out transmission electron microscopic examination of boron powder synthesized by various methods, information on the microstructural characteristics of boron synthesized by electrolytic method has not been reported in the literature. In this study, electron diffraction and phase contrast imaging of electrodeposited boron have been carried out. Phase identification has been attempted based on the analysis of electron diffraction patterns and power spectrum has been calculated from the lattice images from thin regions of the sample.

Richter et al (1973) reported Raman spectra of $\beta$ rhombohedral boron. Approximately 10 broad features were found, a number which is much less than 83 phonons allowed in first order Raman scattering. They reported that symmetry selection rules did not hold for these broad peaks. They were thought to be groups of close lying phonon modes, which might have different symmetry and were broadened by damping.

Kaneshige et al (2007) studied Raman spectrum of $\alpha$-boron under high pressure. They observed no significant change in Raman spectrum between 300 and $1300 \mathrm{~cm}^{-1}$ up to $80 \mathrm{GPa}$, which indicated that $\alpha$-boron kept its icosahedronbased structure up to this pressure. They observed an anomaly in $\omega-P$ curve (Raman shift vs pressure curve) as well as Raman line at around $525 \mathrm{~cm}^{-1}$, which might correspond to some changes in the bonding strength between icosahedral clusters. Similar anomalies were observed by Zhao and Lu (2002) in their Raman studies of $\beta$-boron.

Vast et al (1997) carried out Raman spectroscopic studies on $\alpha$-boron under pressure and compared the results with $a b$ initio lattice dynamic calculations. These authors explained the appearance of a sharp peak at $525 \mathrm{~cm}^{-1}$ as a highly harmonic librational mode of the icosahedron and it mainly involved bond bending.

Kurakevych (2009) in his review article discussed X-ray diffraction pattern, electron energy loss spectrograph and Raman spectra of $\alpha$ and $\beta$ rhombohedral boron.
Bickel et al (1991) studied lattice vibrations of the icosahedral $\alpha$-boron. The highest frequency Raman line arose from the breathing mode, strongly perturbed by the two centred interactions. The lowest observed frequency of Raman line was attributed to $B_{12}$ vibration. These authors described the possible causes for the origin of $525 \mathrm{~cm}^{-1}$ Raman line with anomalous polarization and width. Among these possible causes, the important ones were the accidental degeneracy of an $A_{1 \mathrm{~g}}$ and an $E_{\mathrm{g}}$ mode to account for the anomalous polarization and the presence of bulk impurities of $\mathrm{Cl}_{2}$ and $\mathrm{Si}$. Chlorine is often present in $\alpha$-boron as an impurity and chlorine might have a vibration at $530 \mathrm{~cm}^{-1}$. Si also has a sharp line at $523 \mathrm{~cm}^{-1}$. None of these explanations could account satisfactorily for the anomalous Raman shift.

Kuhlmann et al (1994) studied amorphous boron samples of different origin by Raman spectroscopy. Raman spectra exhibited two broad but distinct maxima. The maxima at $800 \mathrm{~cm}^{-1}$ coincided with centre of the intra-icosahedral vibrations in crystalline boron-rich solids. The second maximum at $1160 \mathrm{~cm}^{-1}$ was attributed to Raman active covalent inter-icosahedral B-B bonds. With this strong Raman maximum, the authors concluded that two centre B-B bonds played a decisive role in the structure of amorphous boron.

Kuhlmann et al (1994) also studied amorphous boron samples by infrared spectroscopy. They reported that a pronounced narrow and medium range order existed in amorphous boron powder due to which definite inter-band transition energy was possible. The absorption spectrum of one of the samples exhibited only a few broad peaks and was typical for an amorphous solid. Crystalline portion in some other sample influenced IR spectrum. In this case, the contribution of the amorphous part was superimposed by numerous narrow absorption bands typical for $\beta$-rhombohedral boron. These authors observed a strong absorption band at $1250 \mathrm{~cm}^{-1}$, which was due to the vibration of a single boron atom in the centre of the unit cell of $\beta$-rhombohedral boron. The absorption band at $1170 \mathrm{~cm}^{-1}$ was probably due to impurities affecting vibration of the central atom. The absorption peaks at lower frequencies could be identified as intra-icosahedral lattice vibrations of $\beta$-rhombohedral boron.

The infrared transmission spectrum of $\alpha$-boron was reported by Golikova et al (1972). A total of six bands were identified in the range from $\sim 400$ to $1300 \mathrm{~cm}^{-1}$. Two rather sharp bands at 705 and $806 \mathrm{~cm}^{-1}$ were very strong. An absorption peak centred at $920 \mathrm{~cm}^{-1}$ was of intermediate strength, while a feature at $548 \mathrm{~cm}^{-1}$ was weak but noticeable. A dip in transmission reported at $1080 \mathrm{~cm}^{-1}$ was very broad, while a feature at $1200 \mathrm{~cm}^{-1}$ was very weak. Werheit et al (1990) also obtained comparable results.

Lattice dynamical studies of crystalline boron carried out by Weber and Thorpe (1975) suggested that the vibrational spectrum of amorphous boron might be expected to be similar to that of $\alpha$-boron or $\beta$-boron if icosahedral units were preserved.

Lannin (1978) reported that infrared absorption in amorphous boron platelets (Berrezin et al 1974) and films (Blum et al 1977) indicated a number of features in the vibrational 
spectrum above $\sim 420 \mathrm{~cm}^{-1}$. This author compared Raman spectra of amorphous boron with infrared spectra reported by Berrezin et al (1974) between 425 and $1250 \mathrm{~cm}^{-1}$ and reported that Raman scattering measurements in most amorphous semiconductors had in fact been rather insensitive to small quantities of impurities (carbon and hydrogen).

In order to get information on the structure, nature of bonding and type of allotrope of boron produced by the molten salt electrolysis method, Raman spectroscopic examination of the electrodeposited boron powder was carried out in this study. Though some work has already been reported in literature on Raman studies of boron $(\alpha, \beta$ and $\gamma$ allotropes of boron), no study has so far been carried out on Raman spectrum of the electrodeposited boron powder. It is important to note that Raman spectra of boron synthesized from different methods are not the same. For example, Kuhlmann et al (1994) reported that the features observed in Raman spectra of amorphous boron and thin boron film deposited by evaporation method were not the same. Hence, it is useful to study Raman spectrum of boron powder synthesized by electrolytic method in order to get an overall understanding of the structure and bonding in electrodeposited boron. In the present study, Raman spectrum was recorded from various regions of the sample and an attempt was made to identify the nature (amorphous/crystalline) of the electrodeposited boron.

\section{Experimental}

Elemental boron was synthesized by the electrolysis of molten potassium fluroborate dissolved in a mixture of molten potassium fluoride and potassium chloride. An electrolytic cell was designed and fabricated to carry out electrolysis, the details of which are given in Jain et al (2008). A salt mixture (batch size: $12 \mathrm{~kg}$ ) having composition, $\mathrm{KCl}$ (70 wt \%), KF (12 wt \%) and $\mathrm{KBF}_{4}(18 \mathrm{wt} \%)$, was used as electrolyte. A high-density ( $\rho \sim 1.87 \mathrm{~g} \mathrm{cc}^{-1}$ ) graphite crucible was used as the container for the electrolyte and also acted as an anode. To electrodeposit boron, a cathode made of mild steel in cruciform was employed. Mild steel was chosen as cathode due to its availability, low cost, ease of fabrication and ease of removal of boron after electrolysis from its surface. Electrodeposition of boron was carried out at $1073 \mathrm{~K}$ and $4.5 \mathrm{~V}$ for about $6 \mathrm{~h}$. During electrolysis, boron was deposited on the mild steel cathode, while chlorine and fluorine were evolved at the graphite anode. After the completion of electrolysis, the cathode was taken out from the cell and quenched in distilled water. The quenched deposit was stored in $0.2 \mathrm{~N} \mathrm{HCl}$ solution. Each deposit contained $\sim 54 \mathrm{~g}$ of elemental boron, indicating the rate of boron deposition to be $9 \mathrm{~g} \mathrm{~h}^{-1}$. The current efficiency of this process was found to be $\sim 80 \%$. Electrodeposited boron was purified by using water and acid leaching. Elemental boron powder of purity $>96 \mathrm{wt} \%$ could be synthesized by this process. The major impurities were found to be iron, nickel, carbon and oxygen (Jain et al 2008).
Flakes of electrodeposited boron were milled to get finer particles of boron for electron transparency and processed by using water and acid leaching method to remove cationic and anionic impurities. Transmission electron microscopic analysis was carried out using JEOL 2000 EX II TEM operated at $200 \mathrm{kV}$. The boron powder was ultrasonicated in methanol and one drop of the suspension was loaded onto the carbon coated grid. The carbon coated grid was dried under an infrared lamp for $8 \mathrm{~h}$ and then loaded into the specimen carousel of TEM.

A high-throughput Renishaw micro-Raman spectrometer (model Invia) was employed to record Raman spectra using $514 \mathrm{~nm}(50 \mathrm{~mW})$ laser excitation. The laser beam was focused to a spot size of about $1 \mu \mathrm{m}$ with $50 \mathrm{X}$ objective and the signal was detected by a charge coupled device (CCD) detector.

\section{Results and discussion}

\subsection{Transmission electron microscopy of boron powder}

The sample consisted largely of thick particles. However, a small fraction of the particles was found to be a few hundred nanometres wide with electron transparent regions mainly at the edges. The dark field micrograph shown in figure 1 was obtained using $\left(\begin{array}{lll}2 & 1 & 1\end{array}\right)$ diffraction spots. The bright contrast in the micrograph indicates the presence of crystallites in that particular region of the specimen. The partial crystalline nature of the sample is revealed by the appearance of less number of bright regions which indicates the presence of less number of crystallites in the sample. The crystallite size was

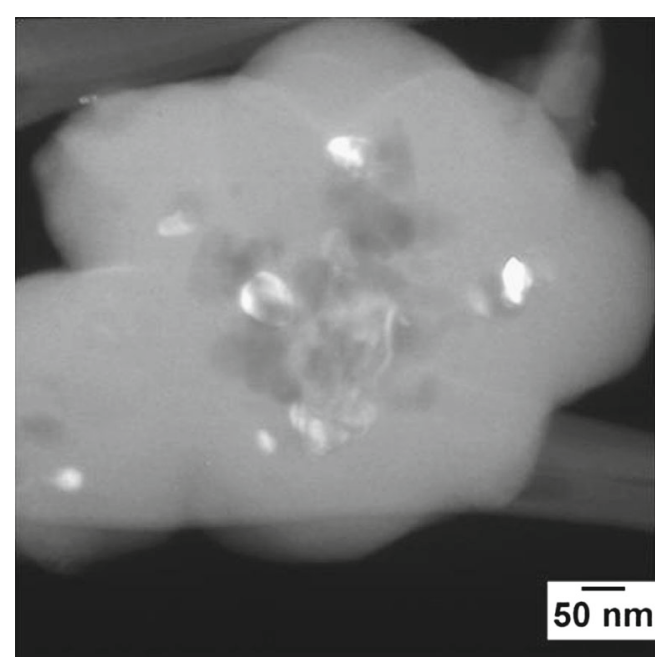

Figure 1. Dark-field image from a portion of boron specimen, synthesized by electrotwinning at a temperature of $1073 \mathrm{~K}$ by applying a potential of $4.5 \mathrm{~V}$ on a mild steel substrate for $6 \mathrm{~h}$. Crystallites of $\beta$-rhombohedral boron having size of $\sim 50 \mathrm{~nm}$ seem to be embedded within an amorphous mass. 


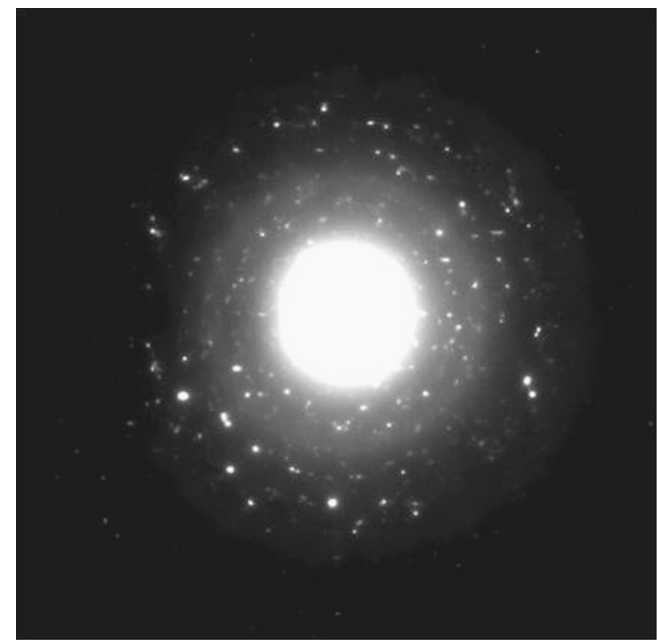

Figure 2. Selected area diffraction pattern of boron specimen, synthesized by electrotwinning at a temperature of $1073 \mathrm{~K}$ by applying a potential of $4.5 \mathrm{~V}$ on a mild steel substrate for $6 \mathrm{~h}$.

Table 1. Indexing of selected area diffraction pattern obtained from figure 2 .

\begin{tabular}{llc}
\hline & \multicolumn{2}{c}{$\begin{array}{c}\beta \text {-boron } \\
\text { PDF \# 80-0322 }\end{array}$} \\
\cline { 2 - 3 } Measured $d(\mathrm{~nm})$ & $d(\mathrm{~nm})$ & $h k l$ \\
\hline 0.355 & $0 \cdot 353$ & 211 \\
0.343 & $0 \cdot 342$ & 122 \\
0.298 & 0.293 & 303 \\
0.287 & 0.286 & 125 \\
0.245 & 0.246 & 217 \\
\hline
\end{tabular}

found to be $\sim 50 \mathrm{~nm}$. The bright regions seemed to be embedded in a dark contrast mass. This indicates the amorphous region in the sample.

The crystalline nature of the sample was revealed in the electron diffraction pattern shown in figure 2. A selected area diffraction pattern showed a prominent halo from the amorphous material and diffraction spots from the crystalline material. The selected area covered a number of particles resulting in a large number of diffraction spots. These were analysed and the results are presented in table 1. Spot measurements were consistent with the crystal structure of $\beta$-rhombohedral boron. The selected area electron diffraction patterns indicated the presence of crystalline boron with $\beta$ rhombohedral crystal structure. Phase contrast images from many of the crystalline regions were recorded. Measurements in real and reciprocal spaces (on power spectra) on these images indicated that these crystallites were of $\beta$ rhombohedral boron (figures 3(a-c)). The interplanar spacings and angles indicated in figure 3(c) agreed well with $0.54660 \mathrm{~nm}$ spacing of ( $\left(\begin{array}{lll}1 & 1 & 0\end{array}\right)$ planes (PDF \# 80-0322) for $\beta$-boron and the calculated angle of $58.31^{\circ}$. A good match was obtained between power spectra calculated from experimental phase contrast images and the diffraction pattern
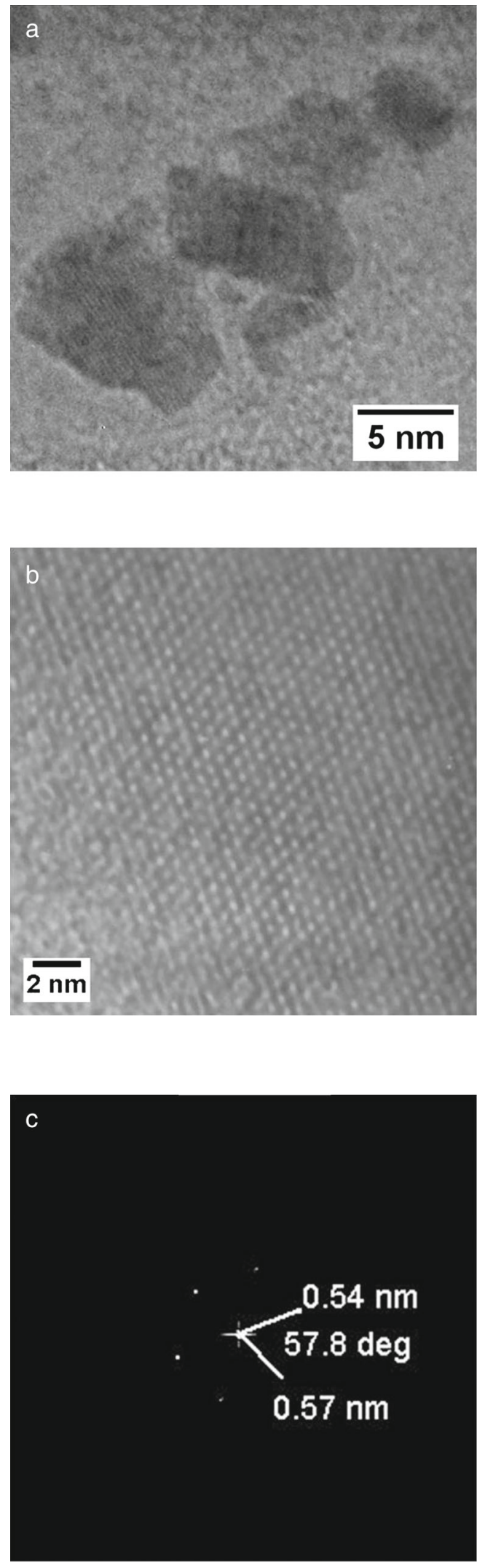

Figure 3. (a) Bright field image of electrodeposited boron specimen showing a crystallite of size $\sim 10 \times 5 \mathrm{~nm}$; (b) phase contrast image of electrodeposited boron specimen showing a resolved lattice and (c) power spectrum of electrodeposited boron specimen generated from figure 3(b) by carrying out Fourier transform. 
geometry for $\beta$-rhombohedral boron. Lattice structure details obtained from lattice images of some other region of the specimen indicated that it might be composed of multiple overlapping grains. A detailed analysis of a selected region of

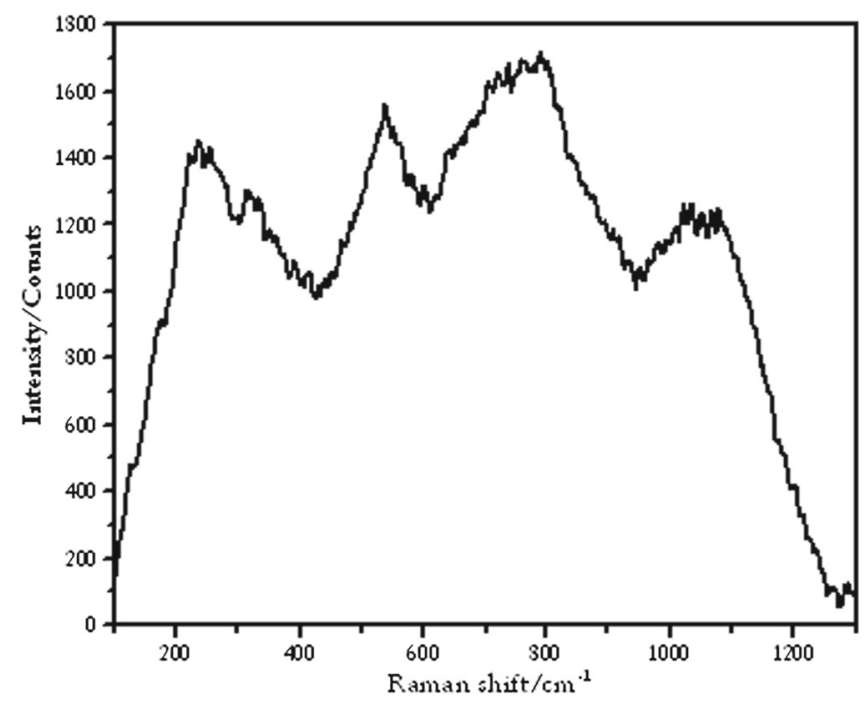

Figure 4. Raman spectrum of electrodeposited boron powder, synthesized by electrodeposition on a mild steel substrate through molten salt electrolysis carried out at $1073 \mathrm{~K}$ by applying a potential of $4.5 \mathrm{~V}$ for $6 \mathrm{~h}$. the lattice image and its power spectrum showed that while the plane spacings could be identified with the expected boron crystal structure, a clear match with respect to interplanar angles was not obtained. This could be due to the presence of other crystalline phases (impurities or due to misorientation effects). The crystallite size estimated from the dark field image is comparable to that reported by Pickering et al (2007) in the organo-capped boron nanoparticles synthesized by reduction of $\mathrm{BBr}_{3}$ with sodium naphthalenide in dry dimethoxyethane. The presence of nanocrystals (size, $\sim 10 \mathrm{~nm}$ ) in the amorphous boron was also observed by Favia et al (1996). Interplanar distances and angles between planes were interpreted with the structure of $\beta$-rhombohedral boron and there was no evidence of a quasicrystalline order. These authors also suggested that the medium range order in the amorphous state was close to the structure of $\beta$ rhombohedral boron. The short range order of the icosahedral type in amorphous boron was confirmed by the same authors in another study by energy loss near-edge structures of boron. Similar results were obtained by Suzuki et al (1995) on amorphous boron filaments grown by electron beam irradiation.

Zhu and Kisi (2009) synthesized boron/boron oxide nanorods by high energy milling and subsequent annealing (in nitrogen) of amorphous boron powder. They described high level of microstrain and high density of structural defects produced due to high energy milling as one of the causes for the formation of nuclei for nanorod growth. In the

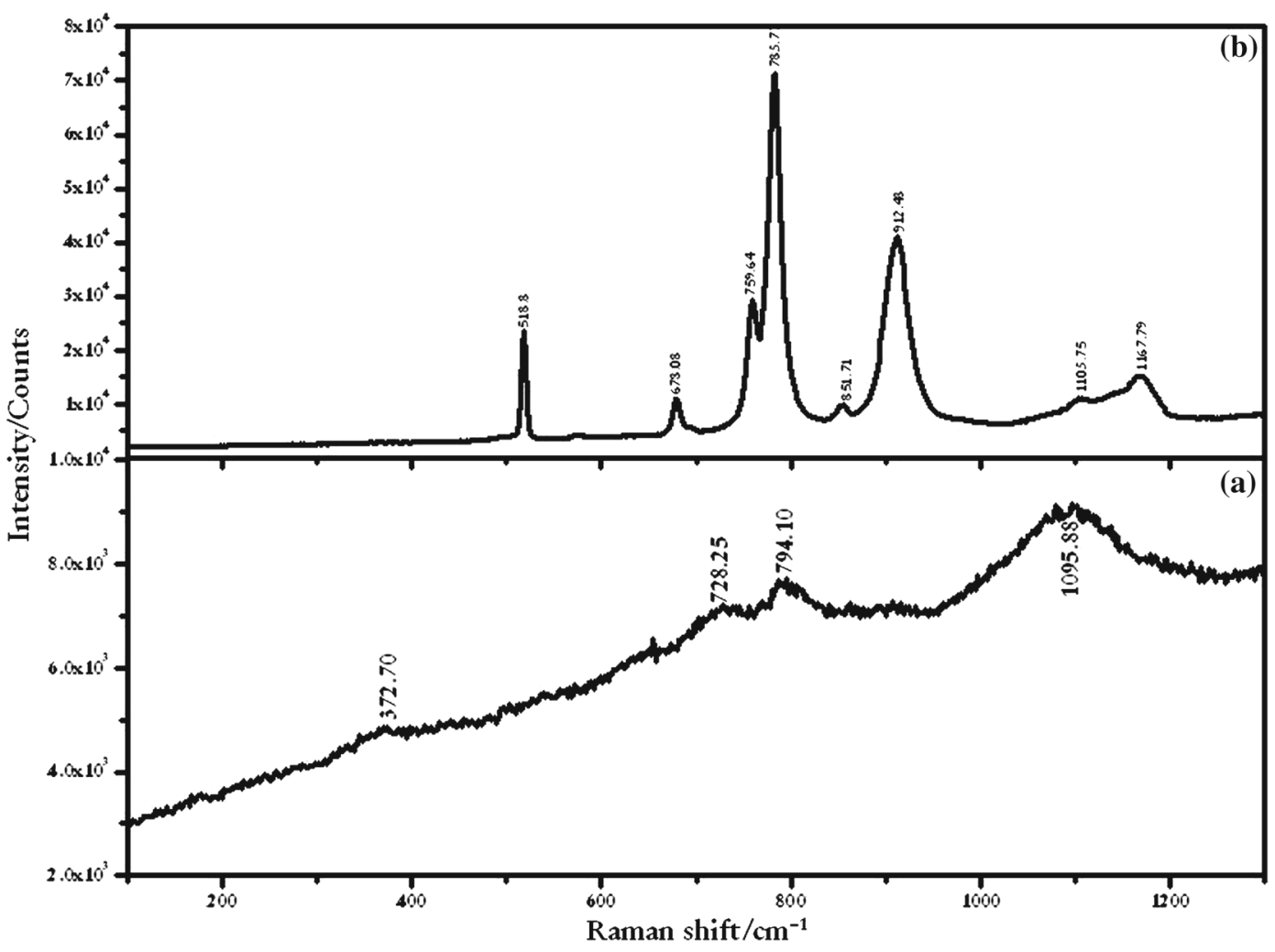

Figure 5. Raman spectrum of electrodeposited boron recorded at two different locations of boron specimen after heat treating electrodeposited boron at $1523 \mathrm{~K}$ for $120 \mathrm{~h}$ under vacuum $\left(10^{-3} \mathrm{mbar}\right)$. 
case of electrodeposited boron, it is first obtained in the form of flakes and during subsequent processing, it was powdered by milling. The appearance of nanocrystallites surrounded by amorphous mass in the dark field image of boron might be due to milling of boron flakes which was carried out during processing or this might be due to first stage of crystallization which could take place during electrodeposition process.

The transmission electron microscopic analysis of boron powder synthesized by Brian et al (2009) using gas-phase pyrolysis of decaborane vapour showed the presence of $\alpha$-rhombohedral phase of boron along with amorphous boron. The reason for the small crystallite size was ascribed to the temperature $(973-1173 \mathrm{~K})$ of the synthesis which was much lower than melting point $(2348 \mathrm{~K})$ of boron. In the present study, although electrodeposition of boron was carried out at $1073 \mathrm{~K}$, amorphous boron along with $\beta$-rhombohedral phase was obtained, as inferred by TEM analysis.

\subsection{Raman spectroscopy of electrodeposited boron}

Raman spectrum of electrodeposited elemental boron powder is shown in figure 4. Raman spectrum does not show any sharp features. The broad features in the spectrum are similar to the spectrum of $\beta$-rhombohedral boron reported by Kurakevych (2009). Absence of sharp bands is due to partial amorphous nature of the sample which is also confirmed by X-ray diffraction pattern. Kuhlmann et al (1994) observed a similar phenomenon and reported that Raman effect in amorphous boron was very weak.

Raman spectrum of electrodeposited elemental boron powder heat treated at $1523 \mathrm{~K}$ and $10^{-3}$ mbar for $150 \mathrm{~h}$ is shown in figure 5 . The spectrum was recorded from several different spots on the sample. A typical spectrum is shown in figure 5(a). The appearance of several Raman bands indicates the formation of crystallites. The conversion of amorphous boron to crystalline boron starts due to heat treatment. The features observed in this spectrum are similar to the one reported by Kuhlmann et al (1994). The bands observed in the spectrum are shown in figure 5(b) corresponding to $\alpha$-rhombohedral boron. This spectrum is similar to the one reported by Evgeniya et al (2008) and Kurakevych (2009). In the present study, the bands observed at 518, 678, 759, $783,851,912,1103$ and $1167 \mathrm{~cm}^{-1}$ are in good agreement with the bands 520, 680, 780, 850, 910, 1100 and 1170 observed by Evgeniya et al (2008). Raman band close to $1160 \mathrm{~cm}^{-1}$ has been reported for crystalline $\alpha$-rhombohedral boron (Werheit et al 1990), $\beta$-rhombohedral boron (Werheit et al 1993), boron carbide (Kuhlmann and Werheit 1993), $\mathrm{B}_{6} \mathrm{O}$ and $\mathrm{YB}_{66}$ and these features are attributed to Raman active covalent inter-icosahedral B-B bonds. Raman spectrum of amorphous boron reported by Lannin (1978) exhibited four peaks at $\sim 270,580,760$ and $1010 \mathrm{~cm}^{-1}$ as well as a shoulder at $\sim 430 \mathrm{~cm}^{-1}$. This author also observed additional structure attributed to lower frequency optic-like phonons as well as acoustic-like modes in Raman spectrum of amorphous boron below $500 \mathrm{~cm}^{-1}$. These bands were not observed in Raman spectrum of electrodeposited boron.

\section{Conclusions}

Structural characterization of the electrodeposited boron was carried out by transmission electron microscopy and Raman spectroscopy. The selected area electron diffraction patterns of boron produced through high temperature molten salt electrolysis method indicated the presence of crystalline boron with $\beta$-rhombohedral phase crystal structure. In most of the places nanocrystals were surrounded by an amorphous mass. The grains were found to be irregular in shape and had an average size of $\sim 50 \mathrm{~nm}$. Raman spectra of electrodeposited boron did not show any sharp features but a spectrum similar to $\beta$-rhombohedral boron was observed as identified in the transmission electron microscopic analysis. Vacuum annealing of boron resulted in its crystallization and Raman bands appeared in this spectrum corresponding to $\alpha$-rhombohedral boron. However, complete conversion of amorphous boron to crystalline boron was not observed under the experimental conditions employed in the present study.

\section{References}

Babu V R, Govindarajan S and Chetal S C 1996 Proc. of seminar on Inherent Engineered Safety Aspects of PFBR Design (Kalpakkam: IGCAR)

Berrezin A A, Golikov O A, Kazanin M M, Khomidov T, Mirlin D N, Petrov A V, Umarov A S and Zaitsev V K 1974 J. NonCryst. Solids 16237

Bickel C L, Yousaf M, Fuka M Z, Raja S Y and Lu N 1991 Phys. Rev. B 442535

Blum N A, Feldman C and Satkiewicz F G 1977 Phys. Status Solidi A41 481

Brian J B, Noh W, Nuzzo R G and Girolami G S 2009 Chem. Commun. doi: 10.1039/b902371b 3214

Evgeniya Y Z, Dubrovinsky L, Dubrovinskaia N, Miyajima N, Filinchuk Y, Chernyshov D and Dmitriev V 2008 Sci. Technol. Adv. Mater. 9044209

Favia P, Stoto T, Carrard M, Stadelmann P A and Zuppiroli L 1996 Microsc. Microanal. Microstruct. 7225

Golikova O A, Drabkin J A, Zaitsev V K, Kazanin M M, Mirlin D N and Nelvson J V et al 1972 Proc. 4th Int. Symp. Boron, Tbilisi 44

Jain A, Anthonysamy S, Ananthasivan K, Ranganathan R, Mittal V, Narasimhan S V and Rao P R V 2008 Mater. Charact. 59890

Kaneshige M, Hirayama S, Yabuuchi T, Matsuoka T, Shimizu K and Mita Y 2007 J. Phys. Soc. Jpn 7619

Kuhlmann U and Werheit H 1993 Phys. Status Solidi B175 85

Kuhlmann U, Werheit H, Lundstrom T and Robers W 1994 J. Phys. Chem. Solids 55579

Kurakevych O O 2009 J. Superhard. Mater. 31139

Lannin J S 1978 Solid State Commun. 25363

Marzik J V, Lewis R C, Tillman M, Wu Y, Finnemore D and Rindfleisch M 2009 Mater. Res. Soc. Symp. Proc. 114812

Marzik J V, Lewis R C, Nickles M R, Finnemore D K, Yue J, Tomsic M, Rindfleisch M and Sumption M D 2010 AIP Conf. Proc. 1219 295 
Miller G T 1960 J. Electrochem. Soc. 107815

Nair K U, Bose D K and Gupta C K 1992 Miner. Proc. Extract. Metall. Rev. 9283

Pickering A L, Mitterbauer C, Browning N D, Kauzlarich S M and Power P P 2007 Chem. Commun. doi: 10.1039/b614363f 580

Richter W, Hausen A and Binnenbruck H 1973 Phys. Stat. Sol. B 60 461

Steeds J W and Wilson J A 1998 J. Appl. Cryst. 31373

Subramanian C and Suri A K 2004 Met. Mater. Process. 1639

Suri A K, Subramanian C, Sonber J K and Murthy Ch. T S R 2010 Int. Mater. Rev. $\mathbf{5 5} 4$
Suzuki S, Tomita M and Hayashi T 1995 J. Appl. Phys. 34 L191

Vast N, Baroni S, Zerah G, Besson J M, Polian A and Grimsditch M 1997 Phys. Rev. Lett. 78693

Weber W and Thorpe M F 1975 J. Phys. Chem. Solids 36967

Werheit H, Kuhlmann U, Solov'ev N E, Tsiskaishvili G P and Tsagareishvili G 1990 Proc. 10th int. symp. boron, borides relat. comp. (Albuquerque, New Maxico) AIP conf. proc. no. 231355

Werheit H, Kuhlmann U, Laux M and Lundstrom T 1993 Phys. Status Solidi B179 489

Zhao J and Lu J P 2002 Phys. Rev. B 66092101

Zhu D M and Kisi E 2009 J. Austr. Ceram. Soc. 4549 